\title{
Numerical optimisation of trawls design to improve their energy efficiency
}

\author{
Daniel Priour ${ }^{\mathrm{a}, *}$
}

a Ifremer, BP 70, 29280 Plouzané, France

*: Corresponding author : D. Priour, email address : Daniel.Priour@ifremer.fr

\begin{abstract}
:
Trawls energy efficiency is greatly affected by the drag, as well as by the swept area regarding pelagic trawls and by the swept width for bottom ones. The drag results in an increase of the energy consumption and the sweeping influences the catch. In order to reduce the drag per swept area (or width) a numerical tool dedicated to the automatic optimisation of the trawl design has been developed. Based on a finite element method model for flexible netting structures, the tool modifies step by step a reference design. For each step the best-modified design, in terms of drag per swept area (or width), is kept. Such a methodology was used in two cases: which show a $43 \%$ increase in energy efficiency regarding the pelagic trawl case and $27 \%$ for the bottom trawl one.
\end{abstract}

Keywords: Fishing gears; Trawl; Modelling; Optimisation; Fuel consumption; Drag; Swept area; Swept width

\section{Introduction}

In 2008, the European fishing firms budget account was severely impacted by the fuel price blow-up, which is the quasi-exclusive energy of this industry: the fuel part in a firm's turnover varies from 10 to over $60 \%$. This impact is not recent but is getting more and more unbearable to fishing firms on account of the fuel cost which has been increasing by around $8 \%$ per year in constant Euro over the last 10 years (Le Floc'h et al., 2007 P. Le Floc'h, J. Boncoeur, F. Daurès and O. Thébaud, Analysing fishermen behaviour face to increasing energy costs-a French case study, ICES ASC Meeting Helsinki, ICES CM 2007/M:09 17-21 September, 2007 (2007).Le Floc'h et al., 2007) and has doubled 
1 over the past year. This effect is even increased on account of the bad state of many fish

2 stocks. Without adaptation, the economic viability of numerous firms will not be guaranteed.

3

4 Trawls, being one of the most common fishing gears, are subject to numerous studies devoted

5 to energy efficiency improvement. These studies also bear on alternative techniques:

6 Macdonald et al. (2007) has tested an alternative to trawling: the jig fishing. But this

7 technique has been tested on areas unsuitable for trawling. Anyway the results indicate that

8 jig fishing could be profitable. Thomsen (2005) has analysed the statistics of 8 ships in the

9 Faeroe Islands fisheries. As the main modification, these ships have been converted from

10 single trawling to pair trawling. It was shown that they kept landings but saved $40-45 \%$ of

11 fuel. Rihan (2005) suggests to turn back to traditional single rig trawling from twin rigs. This

12 has been experimented on Nephrops fisheries in Ireland. The fuel consumption decrease is 13 partly mitigated by the reduction of the catch.

The studies dedicated to trawl optimisation are not recent: During the seventies, large meshes were introduced in the mouth of the trawl, which led to a decrease of the drag and therefore a decrease of the fuel consumption, without affecting the catch. Recently, new twine materials have been tested in some parts of the trawl with the aim of reducing twine diameter and therefore the drag. Ward et al. (2005) studied trawls involving novel materials, which generated a drag cut down by 6\% compared with the usual trawls, and a mouth opening

21 increased by 10\%. Parente et al. (2008) has improved bottom trawls by using larger meshes and by changing the panel cuttings, which led to a potential increase of the net cash flow up to

$2327 \%$. Considering that the drag is also a function of the towing speed many fishermen reduce 24 this parameter in order to lower fuel consumption. 
1 Trawls can be fuel-greedy fishing gears on account of their high drag. In other words their

2 energy efficiency is often very low. In fact, a pelagic trawl must filter a volume of water to

3 catch fish. Considering its swept area or mouth opening, the gear must be towed over a certain

4 distance. The drag energy, or energy required to tow the trawl, is exactly the distance

5 multiplied by the drag. Given the efficiency of the engine and propeller, the fuel energy

6 required is the drag energy divided by this efficiency. In order to increase the energy

7 efficiency, one may increase the efficiency of the engine and propeller, increase the swept

8 area or decrease the drag. This also applies to bottom trawls: they must sweep a bottom

9 surface to catch fish. Their sweeping width, which, for some fish species, may be the distance

10 between wing ends or between doors for others, implies a towing distance. In order to

11 increase the bottom trawl energy efficiency, one may increase the efficiency of both the

12 engine and propeller, increase the sweeping width or decrease the drag. The last suggests that

13 the catch is proportional to the swept area for pelagic trawl and sweeping width for bottom

14 trawl. In fact it is not so clear: numerous works have studied the relation between catch and

15 mouth opening such as Main and Sangster (1981) in case of bottom trawls.

16

17 This paper deals with trawl optimisation by decreasing the drag and increasing the swept area for a pelagic trawl (or the sweeping width for a bottom trawl). The method proposed improves the trawl energy efficiency by altering the panel cuttings according to Parente et al. (2008), though by means of an automatic tool which is based on a numerical method devoted to shape

21 calculation of fishing gears.

23 Yet, such automatic (or numerical) tools for optimisation are not available but only those 24 dedicated to shape calculation: Ferro (1988), Theret (1993), Bessonneau et al. (1998), 25 Niedzwiedz et al. (1998), Tsukrov et al. (2003), Le Dret et al. (2004), Lee et al. (2005) have 
1 developed 3D numerical methods which describe the twines of the net as numerical bars.

2 These techniques take into account a large number of twines for each numerical bar. The

3 forces considered are not only the drag due to the water flow, but also the weight and the

4 buoyancy of the net. Some of the methods also take into account the twine elasticity. The

5 drawback of these models is that they cannot represent netting details smaller than numerical

6 bars. O’Neill (1997) has developed a 2D model for axi-symmetrical structures, such as the

7 trawl cod-end. The twine tension, the mesh opening stiffness and the pressure of the fish catch

8 on the net are taken into account. Another drawback of this modelling is that it is devoted to

9 the only axi-symmetrical structures. To avoid the problem of constrained numerical elements

10 and axi-symmetry hypothesis, and yet take into account further mechanical behaviours, a

11 Finite Element Method (FEM) 3D model of the net based on a triangular element has been

12 developed (Priour 1999, 2001, 2002). The triangle was chosen to describe the surface

13 elements, because it is the simplest surface shape, thus all the netting details can be

14 represented by adjusting the triangle size. The FEM model takes into account the inner twines

15 tension, the drag force on the net due to the current, the pressure created by the fish in the

16 cod-end, the floatability and weight of the net, the mesh opening stiffness and the bending

17 stiffness. The FEM model is able to describe the whole net and cables, which means that for a

18 trawl, the cod-end, the wings, the headline and also the rigging up to the boat are taken into

19 account. Triangular elements model the net while linear elements model the cables, warps and

20 bridles. The drag and shape of structures such as trawls can be calculated with these

21 numerical tools.

22

23 The whole drag of the trawl can be split between the different parts of the structure. Table 1

24 gives the drag of the various parts of a pelagic trawl and a bottom trawl, calculated by the

25 FEM model. It clearly appears that most of the drag is attributable to the netting part. 
2 Trawls mostly consist of several panels of netting. The panels are polygons delimited by

3 segments of straight lines joining their vertices. Now, the question is to make out whether the

4 design of the panels or the panels cutting is optimal in terms of drag per swept area for the

5 pelagic trawl or per sweeping width for the bottom trawl, and therefore in terms of fuel

6 consumption. The following part of the paper proposes an answer in the form of an

7 optimisation numerical tool.

8

\section{3. Methodology}

10 The FEM model described above calculates the drag and the swept area or width of trawls

11 taking into account the following forces exerted on the structure:

12 3.1. The inner tension in twines

$13 T n=E A \frac{n-n 0}{n 0}$

14 Tn: Tension in twines $(\mathrm{N})$,

15 E: modulus of twine elasticity $(\mathrm{Pa})$,

16 A: twine section $\left(\mathrm{m}^{2}\right)$,

17 n0: unstretched length of mesh side(m),

$18 n$ : stretched length of mesh side (m),

19

20 3.2. The drag force exerted on the net by the current

$21 \quad F=\frac{1}{2} \rho C d D L(V \sin \theta)^{2}$

$22 T=f \frac{1}{2} \rho C d D L(V \cos \theta)^{2}$ 
$1 \quad F$ : normal force (N) to the twine. This expression comes from the Landweber hypothesis.

$2 T$ : tangential force which comes from the Richtmeyer hypothesis.

$3 \rho$ : mass density of water $\left(\mathrm{kg} / \mathrm{m}^{3}\right)$,

4 Cd: normal drag coefficient (here 1.2),

$5 f$ : tangential coefficient (here 0.08),

$6 \quad D$ : diameter of the twine (m),

$7 \quad L$ : length of the twine (m),

$8 V$ : amplitude of the current $(\mathrm{m} / \mathrm{s})$,

$9 \theta$. angle between the twine and the current (radian).

10

11 3.3. The drag on the bottom

$12 \quad F C=$ Coef $F v$

$13 \quad F c$ : drag on the bottom $(\mathrm{N})$,

$14 F v$ : vertical force on the bottom $(\mathrm{N})$,

15 Coef: friction coefficient (here 0.5),

16

17 The automatic optimisation of the trawl is carried out step by step. A step consists in an

18 automatic modification of the panels, one by one, vertex by vertex. The FEM model described

19 above calculates the drag and the swept area or width for each modification. The best

20 modification in terms of drag per swept area or width is kept. The steps are repeated until no

21 more improvement is achieved.

22

23 Since the net being the main part of the drag the optimisation concerns the netting parts. The

24 cables, floats and dead weights are not concerned by the modification and thus remain

25 constant along the optimisation process. 
2 The modifications brought to a panel represent a percentage of the maximum size of this

3 panel. For example, the panel given on Figure 1 has a maximum size of 120 meshes vertically

4 and 200 horizontally. A modification of 5\% of this panel will lead to a displacement of each

5 vertex of 6 meshes vertically and 10 meshes horizontally. There will be 16 modifications: 4

6 for each vertex (2 vertically called N \& S and 2 horizontally W \& E). Figure 2 shows the 4

7 modifications of vertex 3 of the panel. In other words, by using the mesh coordinates of

8 vertices, which are for Figure 1: $\left(\begin{array}{l}0 \\ 0\end{array}\right),\left(\begin{array}{c}0 \\ 200\end{array}\right),\left(\begin{array}{l}120 \\ 160\end{array}\right)$ and $\left(\begin{array}{c}120 \\ 0\end{array}\right)$, the panel cutting of Figure 1can

9 be defined by the vector of vertex mesh coordinates $\left(U_{r e f}\right)$ :

$10 \quad U_{r e f}=\left(\begin{array}{c}0 \\ 0 \\ 0 \\ 200 \\ 120 \\ 160 \\ 120 \\ 0\end{array}\right)$

11 By this method, the 16 modifications are defined by the following vectors of mesh

12 coordinates, in which only one figure differs from $U_{\text {ref: }}$ :

134 modifications (N, S, W \& E) for vertex 1: $U_{N}=\left(\begin{array}{c}6 \\ 0 \\ 0 \\ 200 \\ 120 \\ 160 \\ 120 \\ 0\end{array}\right) U_{S}=\left(\begin{array}{c}-6 \\ 0 \\ 0 \\ 200 \\ 120 \\ 160 \\ 120 \\ 0\end{array}\right) U_{W}=\left(\begin{array}{c}0 \\ 10 \\ 0 \\ 200 \\ 120 \\ 160 \\ 120 \\ 0\end{array}\right) U_{E}=\left(\begin{array}{c}0 \\ -10 \\ 0 \\ 200 \\ 120 \\ 160 \\ 120 \\ 0\end{array}\right)$

14 Vertex 2: $\left(\begin{array}{c}0 \\ 0 \\ 6 \\ 200 \\ 120 \\ 160 \\ 120 \\ 0\end{array}\right)\left(\begin{array}{c}0 \\ 0 \\ -6 \\ 200 \\ 120 \\ 160 \\ 120 \\ 0\end{array}\right)\left(\begin{array}{c}0 \\ 0 \\ 0 \\ 210 \\ 120 \\ 160 \\ 120 \\ 0\end{array}\right)\left(\begin{array}{c}0 \\ 0 \\ 0 \\ 190 \\ 120 \\ 160 \\ 120 \\ 0\end{array}\right)$

15 Vertex 3: $\left(\begin{array}{c}0 \\ 0 \\ 0 \\ 200 \\ 126 \\ 160 \\ 120 \\ 0\end{array}\right)\left(\begin{array}{c}0 \\ 0 \\ 0 \\ 200 \\ 114 \\ 160 \\ 120 \\ 0\end{array}\right)\left(\begin{array}{c}0 \\ 0 \\ 0 \\ 200 \\ 120 \\ 170 \\ 120 \\ 0\end{array}\right)\left(\begin{array}{c}0 \\ 0 \\ 0 \\ 200 \\ 120 \\ 150 \\ 120 \\ 0\end{array}\right)$ (shown on Figure 2) 
$1 \quad$ Vertex 4: $\left(\begin{array}{c}0 \\ 0 \\ 0 \\ 200 \\ 120 \\ 160 \\ 126 \\ 0\end{array}\right)\left(\begin{array}{c}0 \\ 0 \\ 0 \\ 200 \\ 120 \\ 160 \\ 114 \\ 0\end{array}\right)\left(\begin{array}{c}0 \\ 0 \\ 0 \\ 200 \\ 120 \\ 160 \\ 120 \\ 10\end{array}\right)\left(\begin{array}{c}0 \\ 0 \\ 0 \\ 200 \\ 120 \\ 160 \\ 120 \\ -10\end{array}\right)$

3 For trawls, which consist of several panels, the vector will be made of vertex coordinates of

4 all the panels. Each vector, or modification, gives a drag and a swept area or width.

5

6 This method of optimisation has been applied to both a pelagic trawl and a bottom trawl:

7 3.4. Pelagic trawl

8 The pelagic trawl, named 57 52, has a footrope and headline length of 57m and lateral ropes

9 length of 52m. It is used for scientific surveys (Massé 1996). The mesh side and the rope

10 lengths are presented on Figure 3. The warps are $200 \mathrm{~m}$ long and the bridles $100 \mathrm{~m}$ long. The

11 panel cuttings of the reference pelagic trawl are given at the top of Figure 4. The towing

12 speed is $2.058 \mathrm{~m} / \mathrm{s}$. The calculation will be carried out from the boat with constant doors: the

13 forces exerted on the doors are assumed to be the same for the reference trawl and the

14 optimised one. A modification of $4 \%$ has been decided on for the optimisation process.

\subsection{Bottom trawl}

17 The design of the bottom trawl, which is used on the research vessel (Anonymous 2000), is

18 displayed on Figure 7 and at the top of Figure 8, the rigging being only partly represented.

19 This trawl is used at a $80 \mathrm{~m}$ depth with warps of $215 \mathrm{~m}$ and bridles of $36.6 \mathrm{~m}$. The towing speed

20 is $1.69 \mathrm{~m} / \mathrm{s}$. In this paper the sweeping width has been chosen to be the distance between the

21 wing-ends and not between doors. More precisely, the swept width is defined here as the

22 mean spread between the bottom and the top wing ends. In this case a modification of $8 \%$ has

23 been decided on for the optimisation process. 
2 Two main numerical parameters control the optimisation process: the discretisation size and

3 the modification size. The influence of these two numerical parameters is analysed.

4

5 3.6. Discretisation size

6 The discretisation size determines the size of the elements used in the model. Here the

7 elements, which model the netting, are triangular. The discretisation size determines the usual

8 distance between nodes, which are used as triangle vertices. This size has a large effect on the

9 calculation duration: a large discretisation size reduces the calculation duration but can affect

10 the optimisation results.

11

12 The effect of this parameter on the optimisation process has been evaluated by recalculating

13 the optimised trawl with different discretisation sizes.

\subsection{Modification size}

16 The modification size determines the size of the modifications of the coordinate in number of

17 meshes of the panel vertices. It can be expected that these sizes induce the same minimum or different local minimums. This can be partly evaluated by recalculating the optimised trawls with different modification sizes.

\subsection{Potential time and money savings}

22 The potential time and money savings generated by this optimisation are evaluated on the

23 following assumptions for both the pelagic and the bottom trawls previously described.

24 i) The first hypothesis is that the quantity of fish caught per year with the optimised 
per year for the two pelagic trawls and the same swept bottom surface for the bottom trawls, on the assumption of a constant density of fish and a constant catchability.

ii) The second hypothesis is that the efficiency of the engine and propeller equals $10 \%$, the energy per litre of fuel equals $10.70 \mathrm{KWh}$ and the fuel costs $0.7 € / l$. These values may be considered as acceptable for 2008 .

iii) The third hypothesis is that the duration of trawling of the reference trawl per year is $10 \mathrm{~h}$ for 200days.

\section{Results}

\subsection{Pelagic trawl}

The calculated drag of the reference trawl is $67226 \mathrm{~N}$ and the swept area is $199 \mathrm{~m}^{2}$, which gives a drag per swept area equal to $337.8 \mathrm{~N} / \mathrm{m}^{2}$. (4)

From this reference calculation, the modifications are calculated for each step. The pelagic trawl comprises 25 panels, which implies 372 modifications per step. In other words, the size

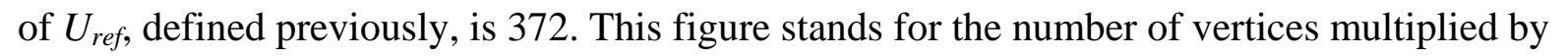
4, this figure being the number of modifications by vertex (N, S, W \& E).

(1)

A percentage of modification of $4 \%$ gives the results displayed on Table 2 for the first step.

This table lists only few of the 372 results achieved for this step.

Table 2 shows that, compared to the reference drag per swept area of $337.8 \mathrm{~N} / \mathrm{m}^{2}$, some modifications give a better result (second line $299.7 \mathrm{~N} / \mathrm{m}^{2}$ ) while some give worse results (seventh line $338.2 \mathrm{~N} / \mathrm{m}^{2}$ ). The minimum value $\left(275.8 \mathrm{~N} / \mathrm{m}^{2}\right.$ ) of the 372 modifications of the 
1 first step is due to the modification on panel 2, node 1 and along a modification $\mathrm{N}$ (also in

2 Table 2). This modification, called the best, is kept and used as reference for the second step

3 and so on. After 34 steps the drag per swept area reaches $146.2 \mathrm{~N} / \mathrm{m}^{2}$. The next step $\left(35^{\text {th }}\right)$

4 doesn't give any further improvement.

6 The evolution of the drag per swept area along the 34 steps is displayed on Figure 5. The drag

7 decrease is larger for the first steps. The drag computed for the last step is $82706 \mathrm{~N}$ and the

8 swept area $552 \mathrm{~m}^{2}$, which gives a drag per swept area equal to $149.8 \mathrm{~N} / \mathrm{m}^{2}$. This drag per

9 swept area compared to the $337.8 \mathrm{~N} / \mathrm{m}^{2}$ of the reference trawl indicates a decrease of $56 \%$.

10 The panel cuttings of the optimised trawl are given at the bottom of Figure 4. Figure 6 shows

11 the shape of both the reference trawl and the optimised one. It can be seen that the swept area 12 increases a lot.

\subsection{Bottom trawl}

15 The calculation of the shape of the reference trawl is displayed on Figure 10 (top). The calculated drag is $64450 \mathrm{~N}$ and the swept width equals $21.7 \mathrm{~m}$, which leads to a drag per swept width of $2973 \mathrm{~N} / \mathrm{m}$ for the reference trawl.

The evolution of the drag per swept width along the 34 steps of the optimisation is displayed on Figure 9. The minimum value is $2176 \mathrm{~N} / \mathrm{m}$. This means a decrease of $27 \%$ when compared

21 to the reference trawl.

23 The panel cuttings of the optimised trawl are given at the bottom of Figure 8. The calculated

24 shape is shown at the bottom of Figure 10. The optimised trawl looks more like a uniform 25 cone than the reference trawl, which could explain the decrease in the drag per swept width. 
1 The calculated drag is $63910 \mathrm{~N}$ and the swept width equals $29.4 \mathrm{~m}$. This means more or less

2 the same drag (-1\%) and a quite large increase in the swept width (35\%).

3

4 This bottom trawl (trawl, bridles and doors) has obviously a drag due to the friction on the

5 bottom. The tool calculates this drag: for the reference trawl a value of $14138 \mathrm{~N}$ and for the

6 optimised one a value of $13204 \mathrm{~N}$ were found for bottom drag. This small decrease (7\%)

7 could lead firstly to a decrease in the catch efficiency, due to a smaller efficiency in terms of

8 fish lifted from the bottom, and secondly to a smaller impact on the bottom. The vertical

9 opening is $3.6 \mathrm{~m}$ versus $3.2 \mathrm{~m}$ for the reference trawl. This increase (12\%) could lead also to 10 an increase in the catch efficiency.

11

12

4.3. Analysis of the influence of the discretisation size

13

The optimisation results given for the pelagic trawl have been achieved for a discretisation size of $3 \mathrm{~m}$, a large one in order to limit the duration of the calculation. The influence of the discretisation size is analysed by calculating the optimised trawl with 6 discretisation sizes: from $0.8 \mathrm{~m}$ to $5 \mathrm{~m}$. The result is given in Table 3 . This gives similar reductions of the drag per swept area (from 43\% to 56\%), but not close. This means that the optimisation, being carried out with a pretty large discretisation size in order to limit the time of calculation, may be confirmed using a smaller discretisation size. This means that the method may be sensitive to this parameter, but the potential error due to this sensitivity may be cancelled by using a

21 smaller discretisation size on the result obtained by the large discretisation size. The bottom trawl has been optimised using a discretisation size of $2 \mathrm{~m}$ which has been considered small enough. 
2 The optimisation results have been achieved for a modification size of $4 \%$ for the pelagic

3 trawl and 8\% for the bottom one. The influence of the modification size is analysed by

4 calculating the optimisation of the pelagic trawl with 4 modification sizes (from 1\% to 8\%).

5 The result provided in Table 4 shows a drag per swept area variable between the modification

6 sizes (from 149.8 to $183.1 \mathrm{~N} / \mathrm{m}^{2}$ ). It is clear that the minimum found with a modification size

7 of $4 \%\left(149.8 \mathrm{~N} / \mathrm{m}^{2}\right)$ is not the same as the one found for $2 \%\left(183.1 \mathrm{~N} / \mathrm{m}^{2}\right)$. This means that

8 the method is sensitive to this parameter even though the reduction of drag per swept area

9 remains quite large for each modification size.

\subsection{Potential time and money savings}

The main results, in terms of time and money savings, for the two pelagic trawls of Figure 6 are displayed in Table 5. On these assumptions, and especially assuming a same filtered volume per year for both the trawls, the duration per year is decreased by 101 days with the optimised trawl and the expected economy on the fuel cost may amount to $77000 €$ per year. The results for the two bottom trawls of Figure 10 are provided in Table 6. The optimisation leads to a decrease of 52 days of the number of days at sea per year and expected savings on the fuel cost of $38000 €$ per year.

\section{Discussion and conclusion}

21 The effect of the modification size has been studied on the pelagic trawl with 4 sizes from $1 \%$ to $8 \%$ (Table 4). They lead to relatively large differences, which indicate that they reach different minimums, but yet, induce significant decrease in drag per swept area. It seems difficult to predict which modification size (small or large) will lead to the larger decrease of

25 drag per swept area. 
2 The effect of the discretisation size has been studied on the pelagic trawl with 6 sizes from

$30.8 \mathrm{~m}$ to $5 \mathrm{~m}$ (Table 3). The reductions (43\% to 56\%) of drag per swept area indicate that the

4 discretisation size may affect the result and may be verified using smaller discretisation sizes.

6 In the method described here the fishing gears have been optimised in terms of drag per swept

7 area or per swept width. It may be decided to optimise the gear in terms of drag only, but in

8 this case the dimensions of the netting may be reduced; thus, some constraints may be

9 introduced in this case. These constraints, which have not been implemented yet, may consist

10 in maintaining some parameters such as the swept area, or the vertical opening, the horizontal

11 opening and so on.

13 It is obvious that, in the mouth of the trawl, the ropes (head-rope and foot-rope) have a large

14 effect on the swept area or the swept width. It may be planned to adjust automatically the 15 length of the cables in order to optimise the gear. Considering the bottom trawl, the vertical opening increases from the reference trawl to the optimised one (Figure 10). In some cases

17 this increase is not expected. An automatic variation of the floatability of the head-rope may 18 be integrated in this method to adjust the vertical opening.

In the method described here the modification sizes are fixed (e.g. $2 \%, 4 \%, 8 \%$ ) and assessed

21 vertex by vertex. Another strategy may be used to find a minimum. A maximal modification

22 per vertex in each direction may be imposed (e.g. 10\%). A modified gear would mean a modification of the vertices all together. The modification would be a random value for each

24 vertex. The random value would be between 0 and the maximal modification. Numerous

25 modified trawls would be calculated, e.g. 1000 or 10000 . The best in terms of drag per swept 
1 area (or width) would be kept. With this strategy it may be expected to reach a better optimal

2 case than with the strategy described in this paper. In fact, a lot of scientific works have been

3 devoted to optimisation (Haslinger J. \& Makinen R.A.E., 2003), but not for fishing gears.

4 Such works define standard methods that could be applied to trawl optimisation.

6 This tool provides a way to increase the energy efficiency, but it cannot be used alone. Trawl 7 designers may use the results of this tool in order to optimise their designs. In fact they may 8 use the design obtained with the tool and then modify it by hand. If the modifications are not 9 too extensive, the professional will keep the main gain of the tool.

11 Due to the large number of trawl calculations (up to 10 000), the tool may take a long time:

12 20h for the optimisation of the pelagic trawl on Figure 6, and 7h for the bottom one on Figure 13 10. It would be profitable to use the full capacity of a Personal Computer and especially the 14 multi cores.

Such improvement in the fishing gear must be carried out taking into account the biological situation of the stock of concern: this technique must be applied only in the case of wellmanaged stocks. It may cause considerable damage to the fishery to use such a technique on depleted fish stocks.

21 Even trawls, just as any other fishing gear, have, generally, a large handicap due to fuel 22 dependency and impact on the biomass; thus, it is expected that for the trawls currently used, 23 such a numerical tool may, in the future, contributes to increase energy efficiency and 24 therefore to reduce dependency to fuel. 


\section{Acknowledgements}

2 The author wants to thank the reviewers for their constructive remarks that have contributed

3 to improve significantly the paper.

4

\section{7. References}

6 Anonymous, 2000. Development of predictive model of cod-end selectivity. Final report to

7 the European commission of the RTD project Fair Program CT96 1555.

8

9 Bessonneau J.S. and Marichal D., 1998. Study of the dynamics of submerged supple nets, 10 Ocean Engineering, 27, (7)),

11

12 Ferro RST., 1988. Computer simulation of trawl gear shape and loading, Proceedings of 13 Word Symposium on Fishing Gear and Fishing Vessel Design, Marine Institute, Saint John's, 14 1988, pp. 259-262.

15

16

Haslinger J. and Makinen R. A. E., 2003, Introduction to Shape Optimization: Theory,

17 Approximation, and Computation, SIAM, Philadelphia.

18

19

Le Dret, H., Priour, D., Lewandowski, R., and Chagneau, F. 2004. Numerical Simulation of a

Cod End Net Part 1: Equilibrium in a Uniform Flow. Journal of Elasticity, 76(2), 139-162.

21

22 Lee, C-W., Lee, J-H., Cha, B-J., Kim, H-Y. and Lee, J-H., 2005. Physical modeling for

23 underwater flexible systems dynamic simulation. Ocean Eng., 32, 331 - 347. 
1 Le Floc’h P., Boncoeur J., Daurès F., \& Thébaud O., 2007. Analysing fishermen behaviour

2 face to increasing energy costs-A french case study, ICES ASC meeting Helsinki, ICES CM

3 2007/M:09, 17-21 September 2007.

4

5 Macdonald P., Laurenson C., Johnson A. and Tait L., 2007. Jig fishing pilot study in Shetland 6 coastal waters. NAFC Marine Centre. Fisheries development note N.25 September 2007.

7

8 Main and Sangster, 1981 J. Main and G.I. Sangster, A study of the fish capture process in a

9 bottom trawl by direct observations from a towed underwater vehicle, Scott. Fish. Res. Report 1023 (1981), pp. 1-23.

11

12 Massé J., Koutsikopoulos C., and Patty W., 1996. The structure and spatial distribution of 13 pelagic fish schools in multispecies clusters: an acoustic study, ICES Journal of Marine Science, 53: 155-160.

15

16

Niedzwiedz, G. and Hopp, M., 1998. Rope and net calculations applied to problems in marine engineering and fisheries research, Archive of Fishery and Marine Research, 46, 125 - 138.

O’Neill F.G., 1997. Differential equations governing the geometry of a diamond mesh codend of a trawl net, Journal of applied mechanics, March 1997, Vol. 64/7, 453, 7 - 14.

21

22 Parente J., Fonseca P., Henriques V. and Campos A., 2008. Strategies for improving fuel 23 efficiency in the Portuguese trawl fishery, Fisheries Research 93 117-124 
1 Priour, D., 1999. Calculation of net shapes by the finite element method with triangular

2 elements. Communications in Numerical Methods in Engineering, 15(10), 755-763.

3

4 Priour D., 2001. Introduction of mesh resistance to opening in a triangular element for

5 calculation of nets by the finite element method. Communications in Numerical Methods in

$6 \quad$ Engineering, 17 (4), 229 - 237.

7

8 Priour D., 2002, Analysis of nets with hexagonal mesh using triangular elements, Int. J.

9 Numer. Meth. Engng., 56, p 1721-1733. DOI: 10.1002/nme.635.

11 Rihan D., 2005. A comparison of twin-rig and single-rig trawling in terms of relative fishing 12 efficiency, in Economic performance and fishing efficiency of marine capture fisheries, FAO 13 fisheries technical paper 482, ISSN 0429-9345.

Theret, F., 1993. Etude de l'équilibre de surfaces réticulées placées dans un courant uniforme; application aux chaluts. PhD Thesis, Ecole Centrale de Nantes. performance and fishing efficiency of marine capture fisheries, FAO fisheries technical paper 482, ISSN 0429-9345.

21 modeling of net panels using a consistent net element, Ocean Engineering Volume 30, Issue 2, February 2003, Pages 251-270. 
1 Ward, N., Montgomerie, M., Lart,W., 2005. Fuel efficiency trials using Jackson trawls with

2 reduced twine diameter on MFV Challenge II Seafish Report No. SR578, p.31. 


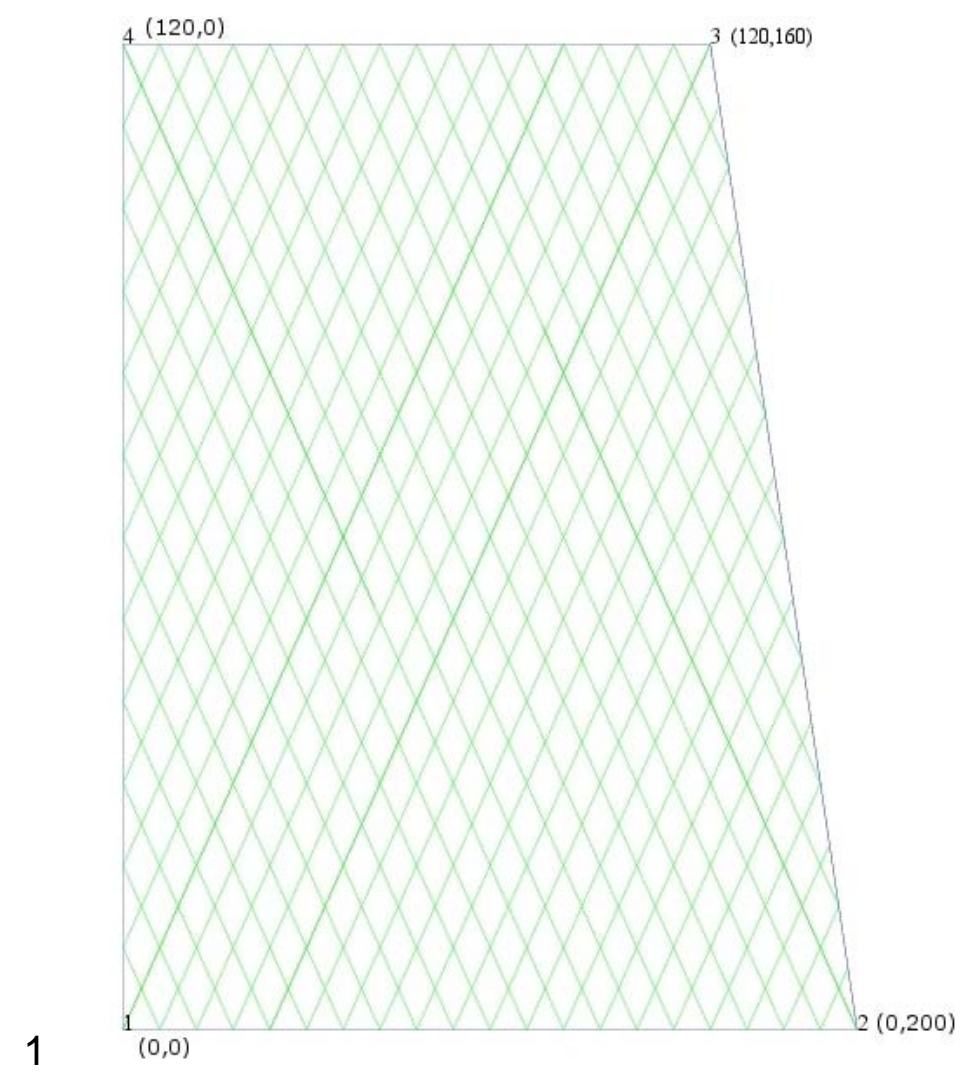

2 Figure 1: Panel of netting of 120 meshes high, 160 meshes on the top horizontal border and 3200 on the bottom one. Only one twine out of tens is drawn. The number of meshes of nodes 4 is noted. The origin of meshing is node 1. 

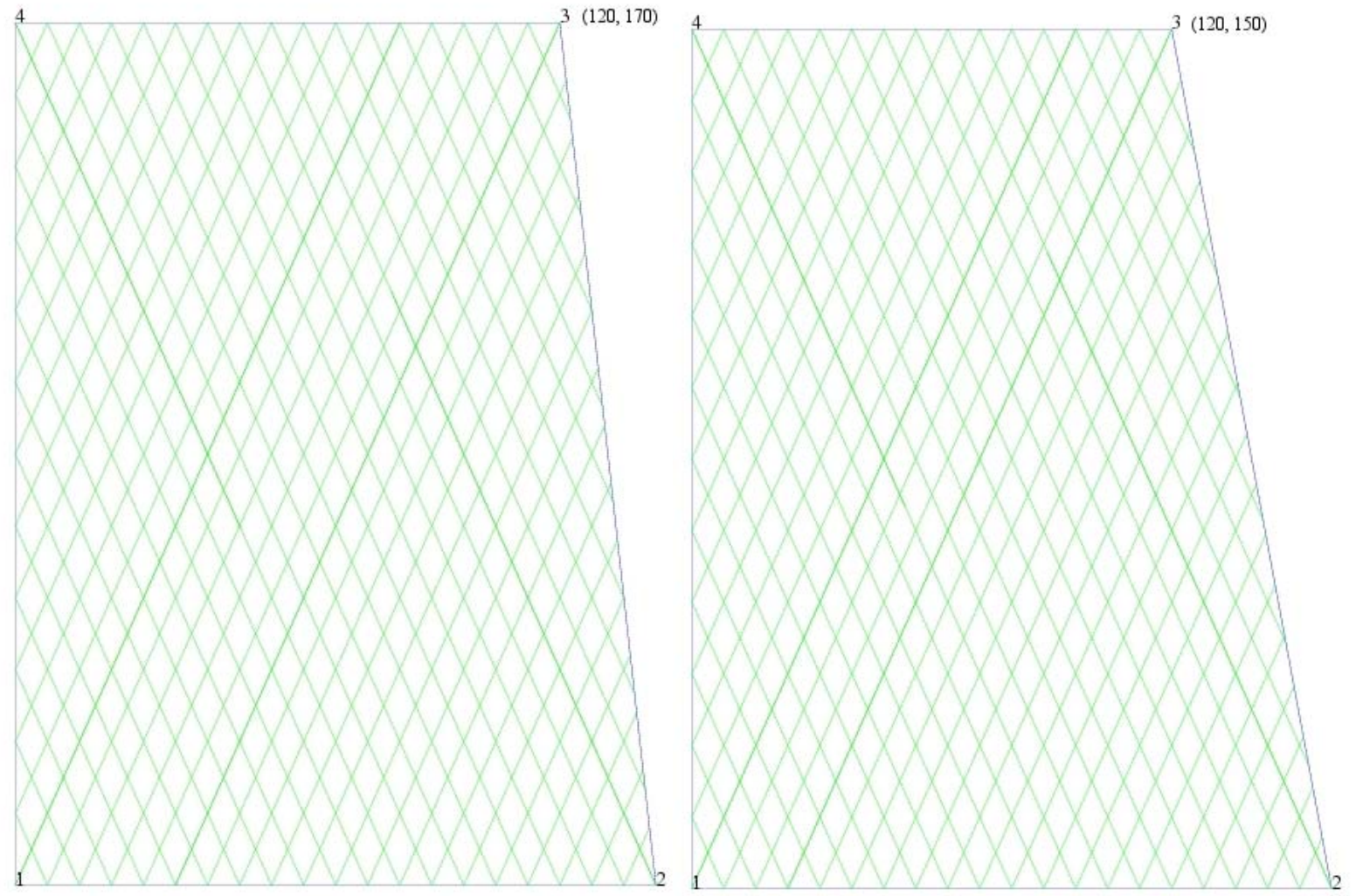

1 $3(126,160)$
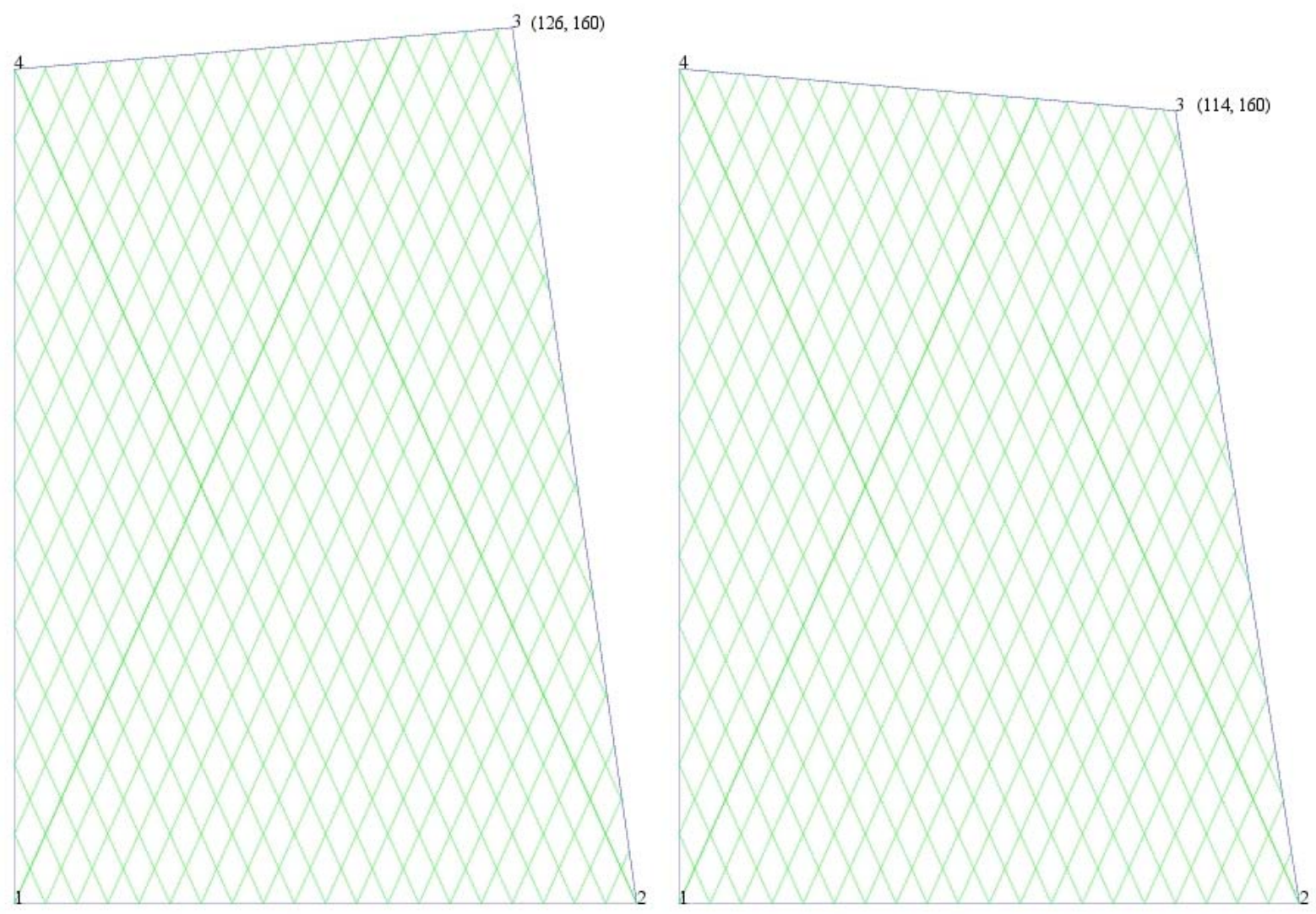

3 Figure 2: The 4 modifications of the node 3 are shown: horizontally on the top (W \& E) and 4 vertically on the bottom ( $\mathrm{N} \& \mathrm{~S}$ ). 


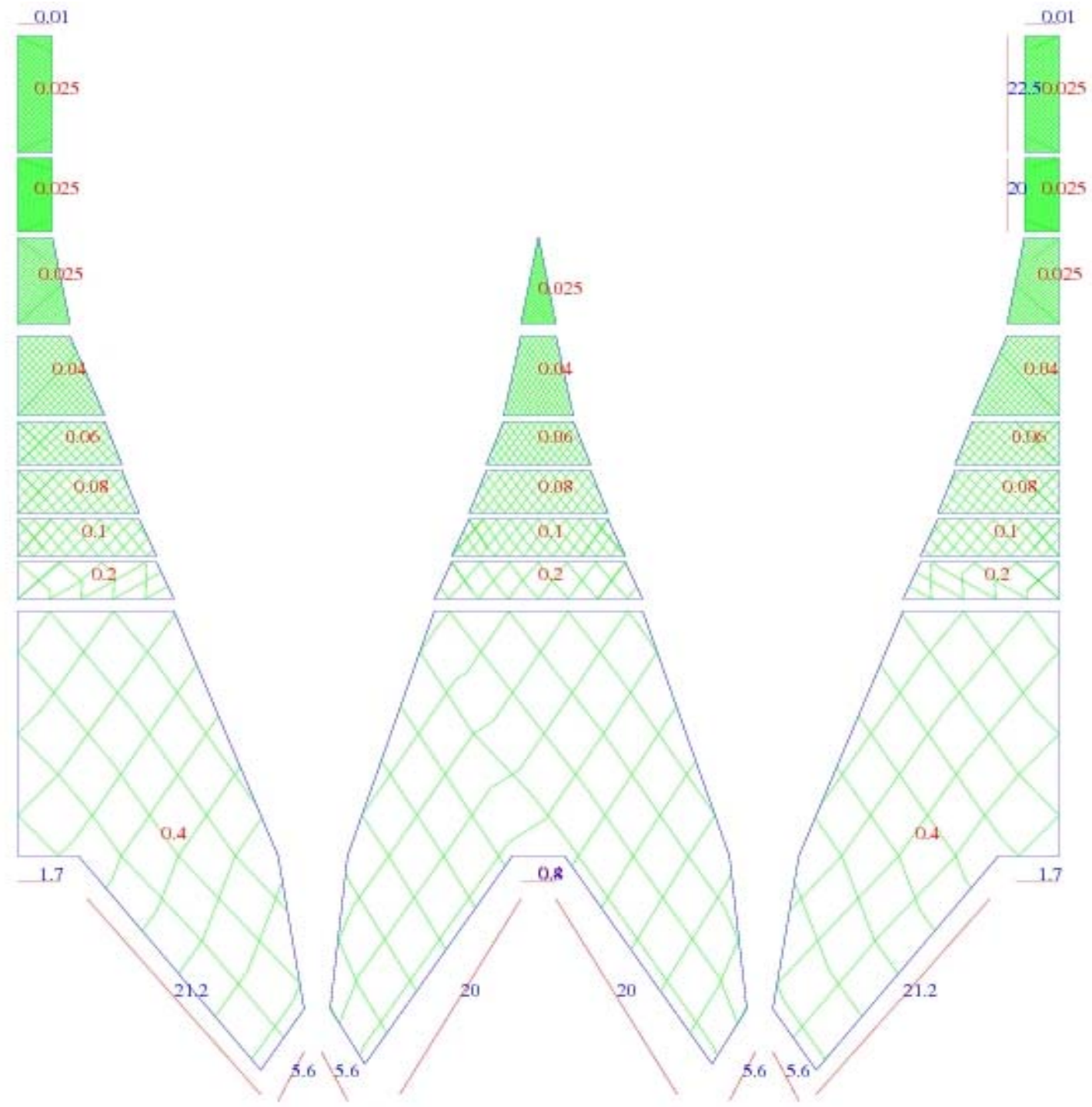

2 Figure 3: Mesh side (half mesh size) and cable length of the pelagic trawls (reference and

3 optimised). The values are in $\mathrm{m}$. The panels and few ropes are represented. Due to the

4 symmetry of the trawl only half part of the back and the belly are presented. Due to the large

5 number of twines only 1 twine out of 5 is drawn. 


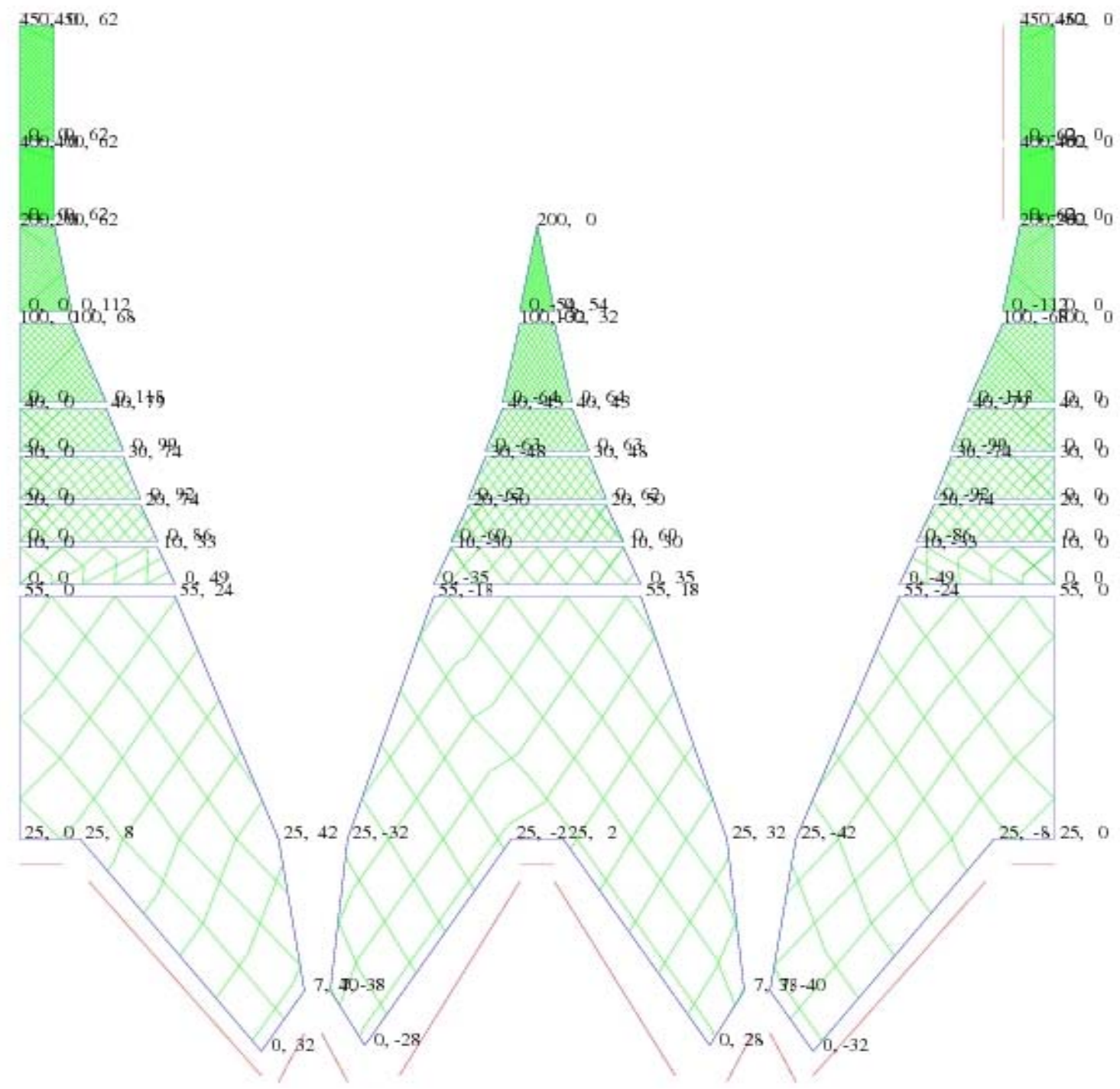




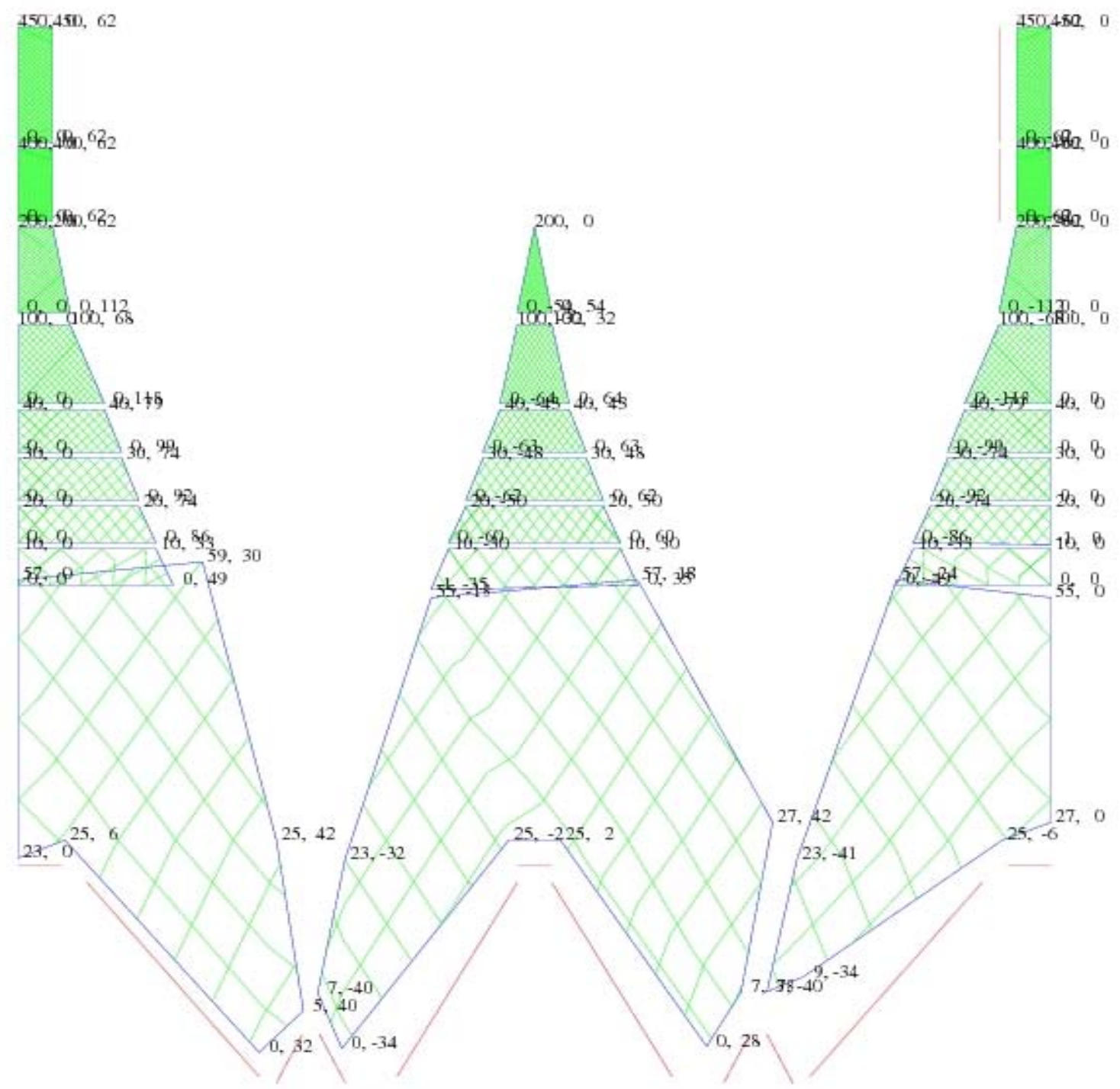

1

2 Figure 4: Design of the reference pelagic trawl (top) and the optimised one (bottom). The

3 number of meshes of vertices is noted. The optimisation has modified mostly the panels of the 4 trawl entry. 


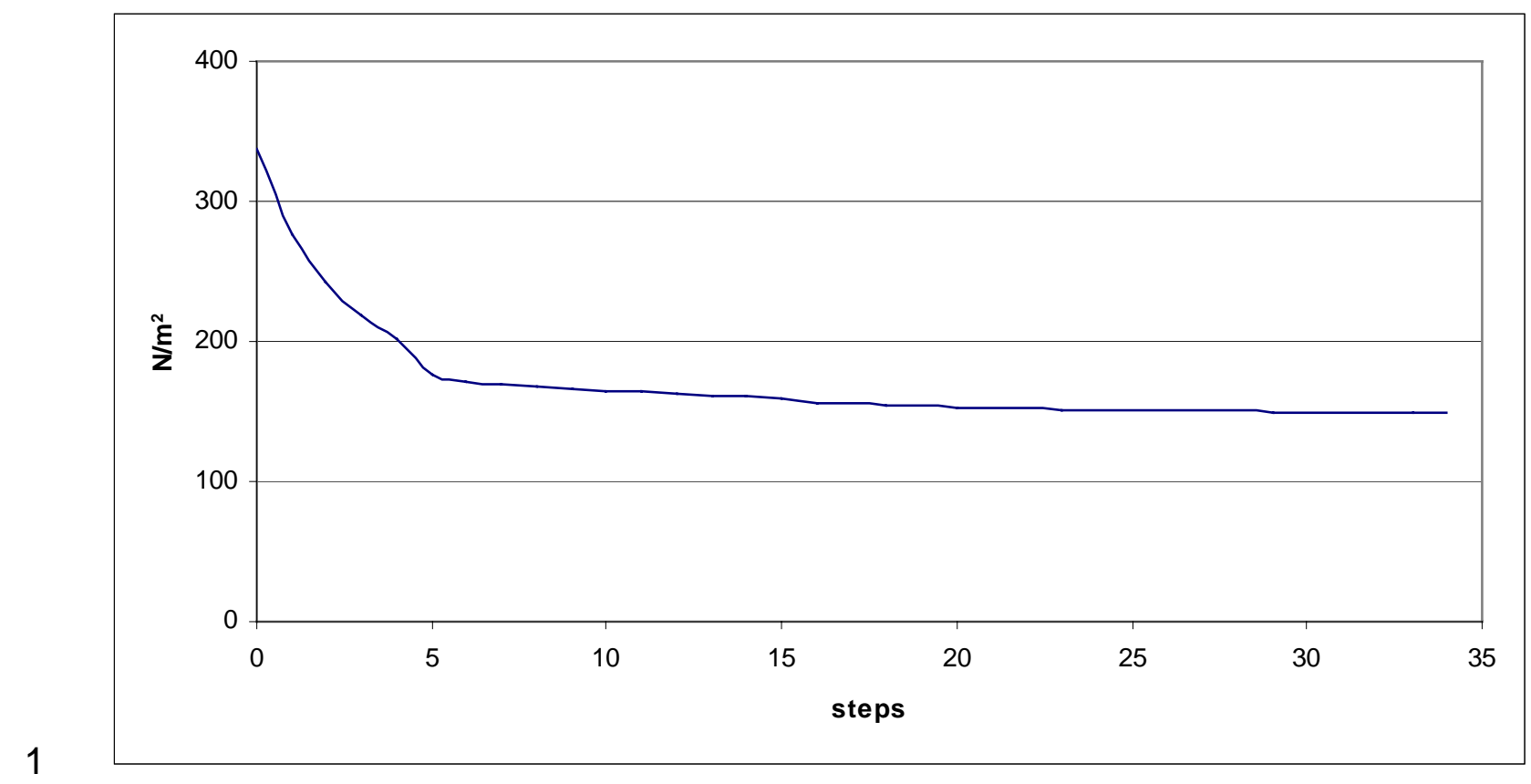

2 Figure 5: Minimum drag per swept area for the 34 steps of the optimisation. Step 0 refers to 3 the reference trawl. 
1

2 Figure 6: Shapes of the reference trawl (left) and optimised one (right). Only 1 twine on 5 are 3 drawn. 

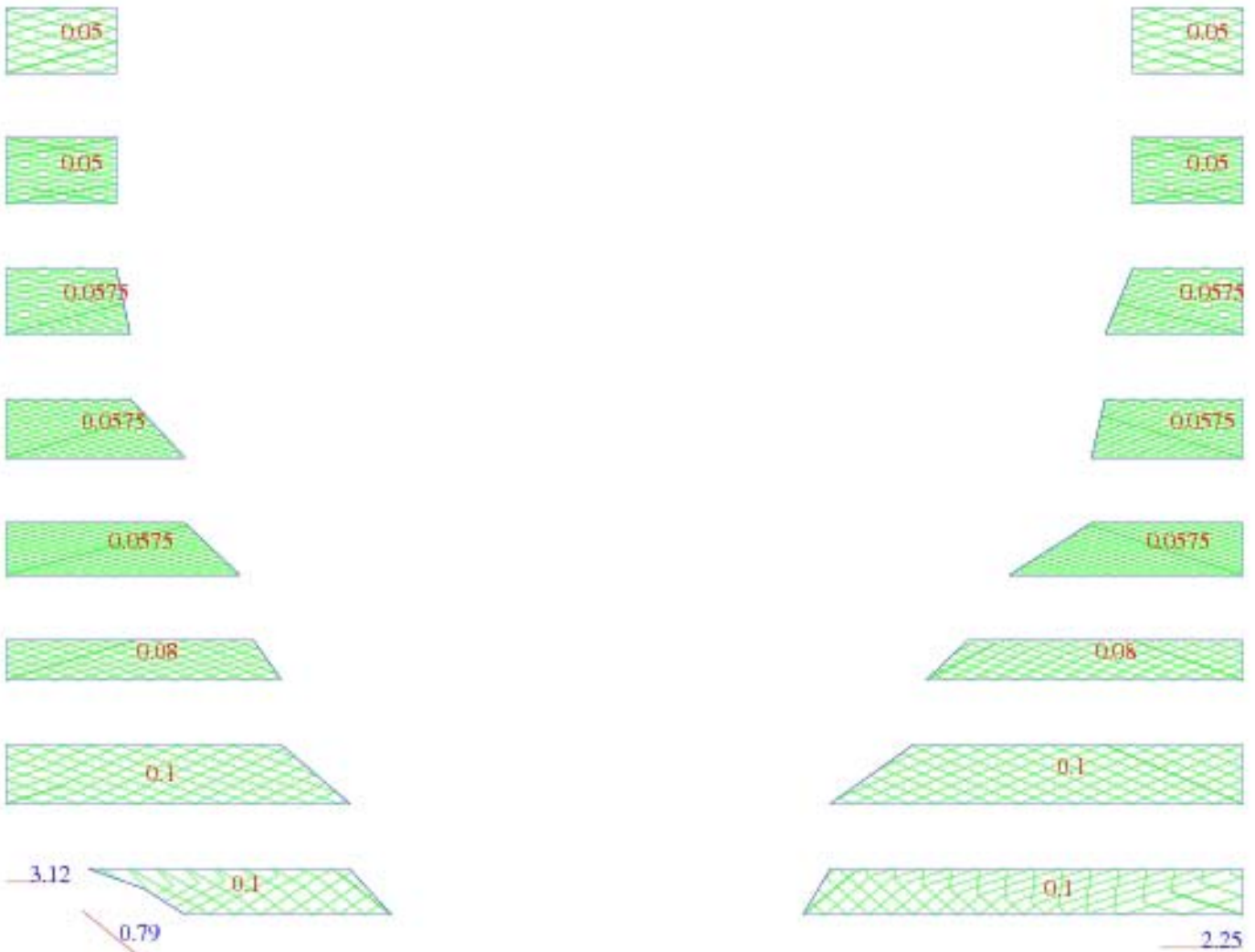

2.25
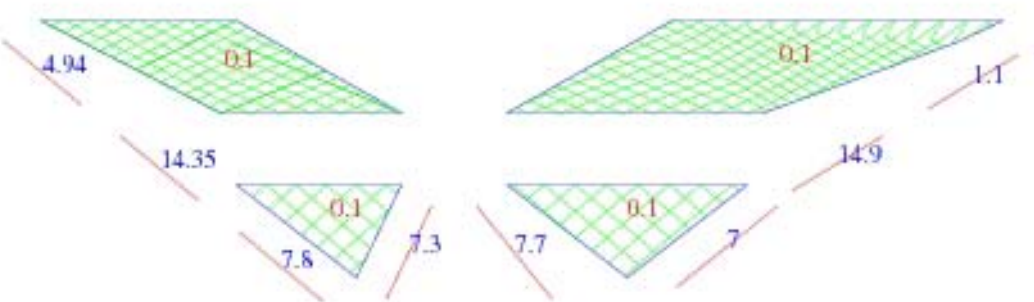

2 Figure 7: Mesh side (half mesh size) and cable length of the bottom trawls (reference and

3 optimised). The values are in $\mathrm{m}$. The panels and few ropes are represented. Due to the

4 symmetry of the trawl only half part of the back and the belly are presented. Due to the large

5 number of twines only 1 twine out of 10 is drawn. 


$$
\begin{array}{ll}
52,0 & 52,-25 \\
0,0 & 0,-25 \\
100,0 & 100,-30 \\
0,0 & 0,-30 \\
100,0 & 100,-30 \\
0,0 & 0,-63
\end{array}
$$
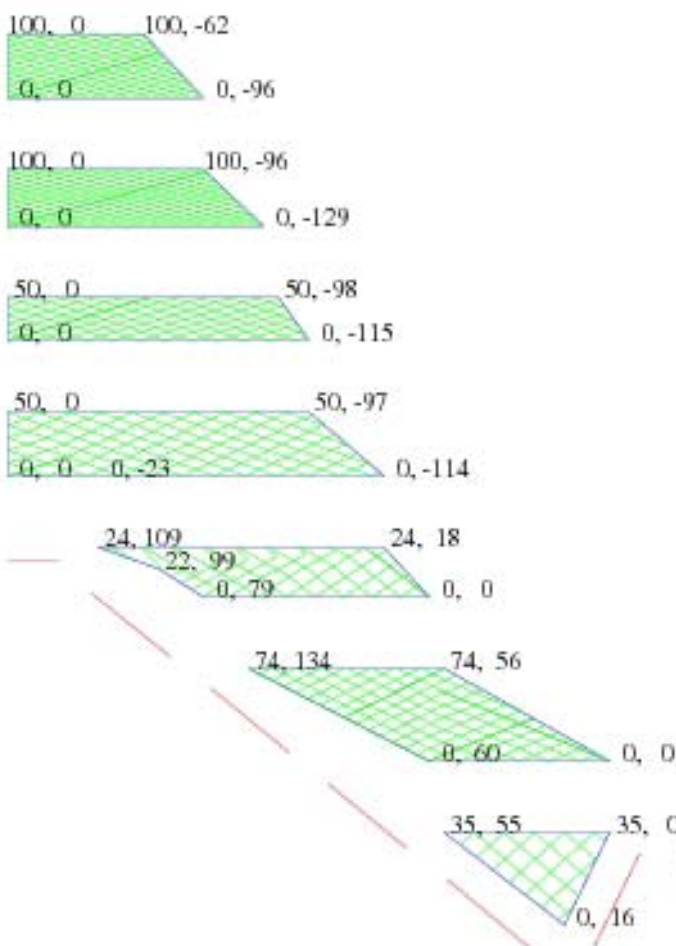

52. $25 \quad 52,0$

$0.25=30$

$100,30 \quad 100,0$

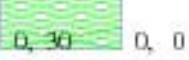

100, $30 \quad 100,0$

$0.63=0,0$

$100,62 \quad 100,0$

$0.96=0,0$
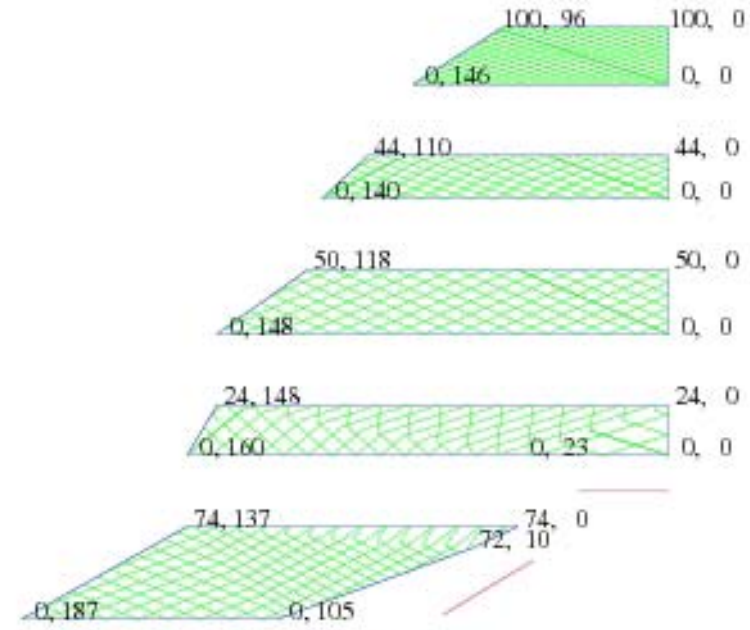

35, $\theta$

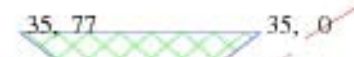



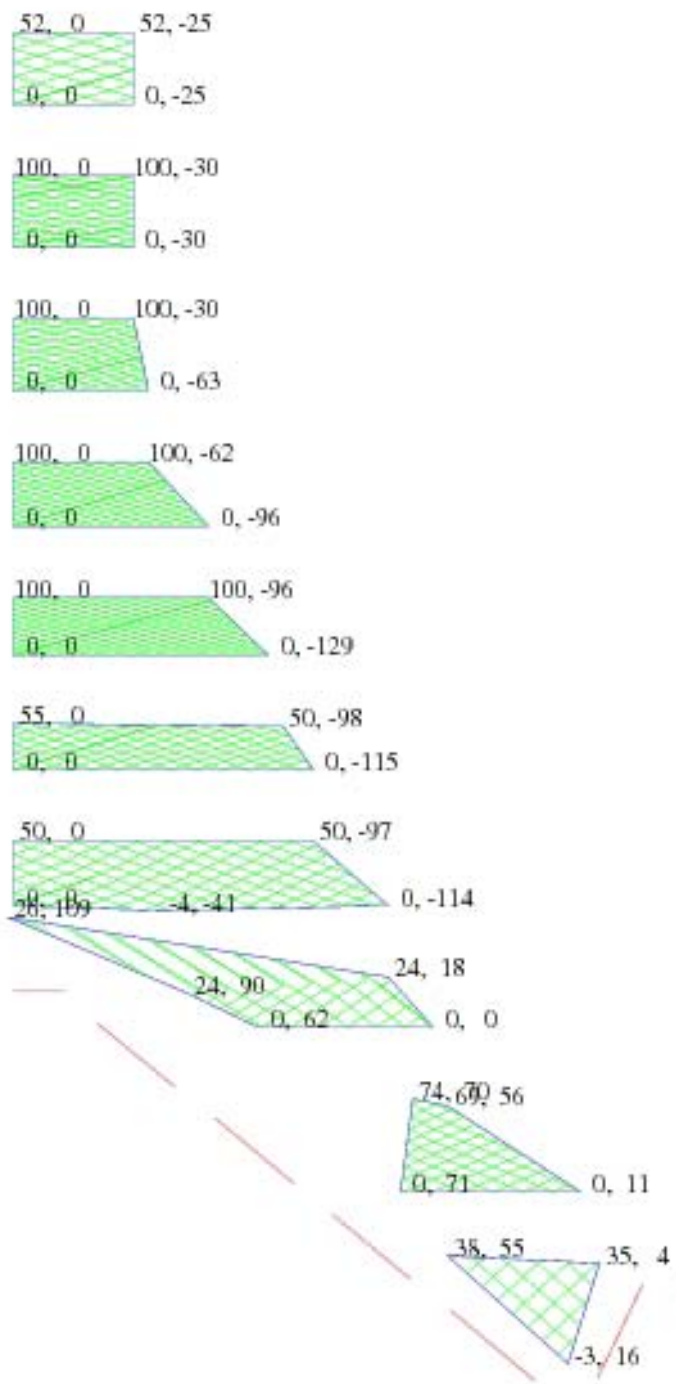

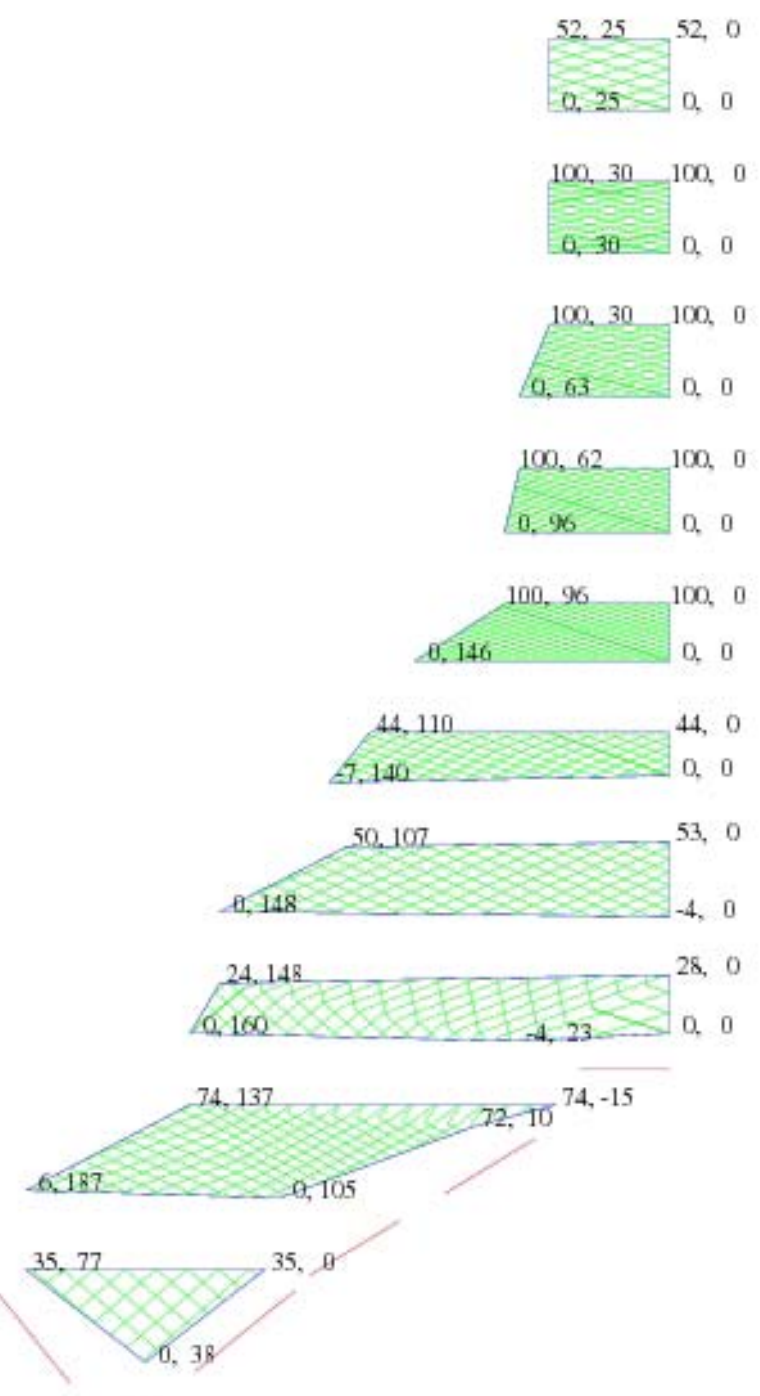

1

2 Figure 8: Design of the bottom trawl (top) and the optimised one (bottom). The number of

3 meshes of the vertices is noted. The optimisation leads to a modification of panels mostly in 4 the mouth of the trawl. 


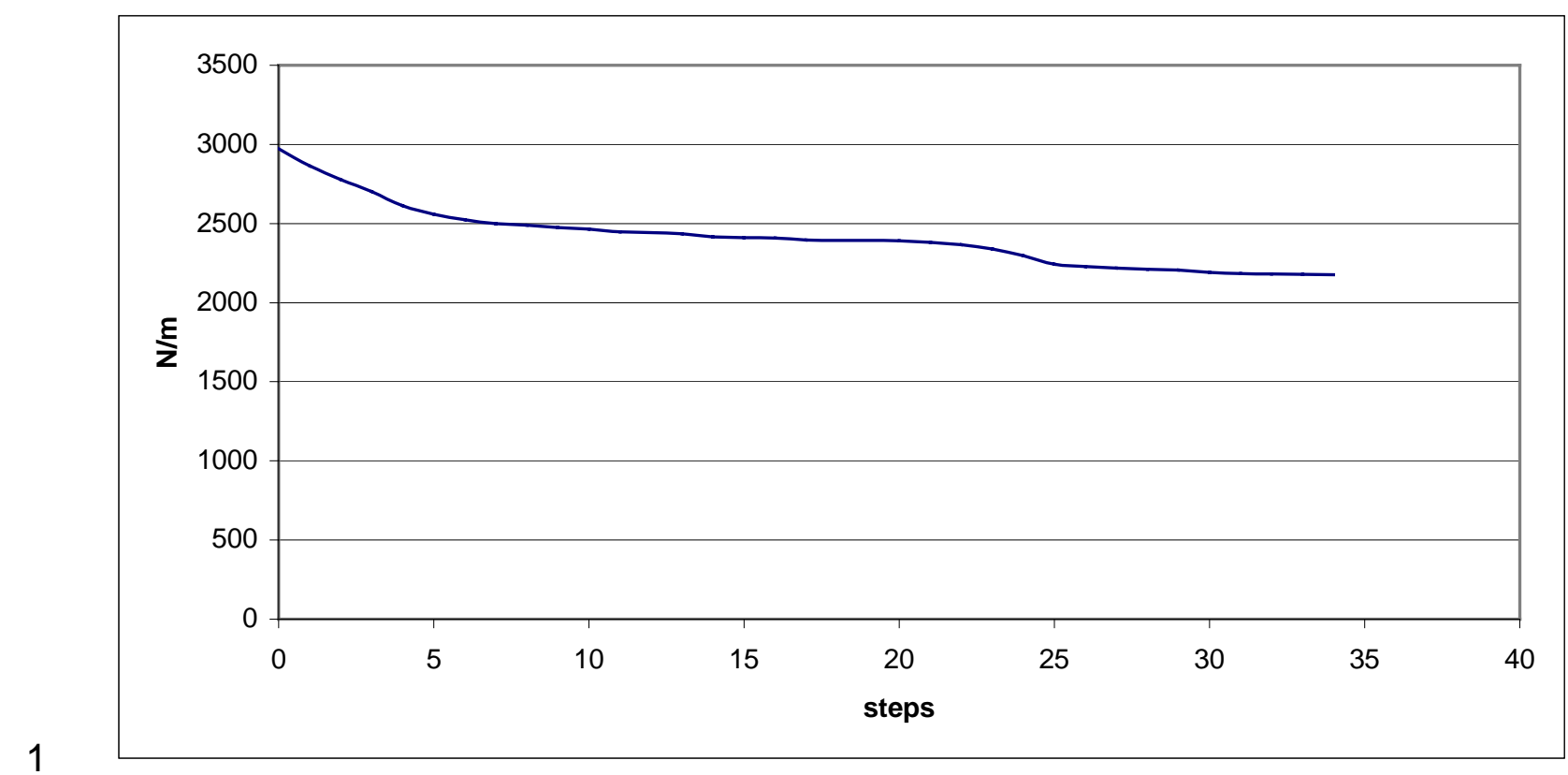

2 Figure 9: Minimum of drag per swept width for the 34 steps of the optimisation. Step 0 refers

3 to the reference trawl. 


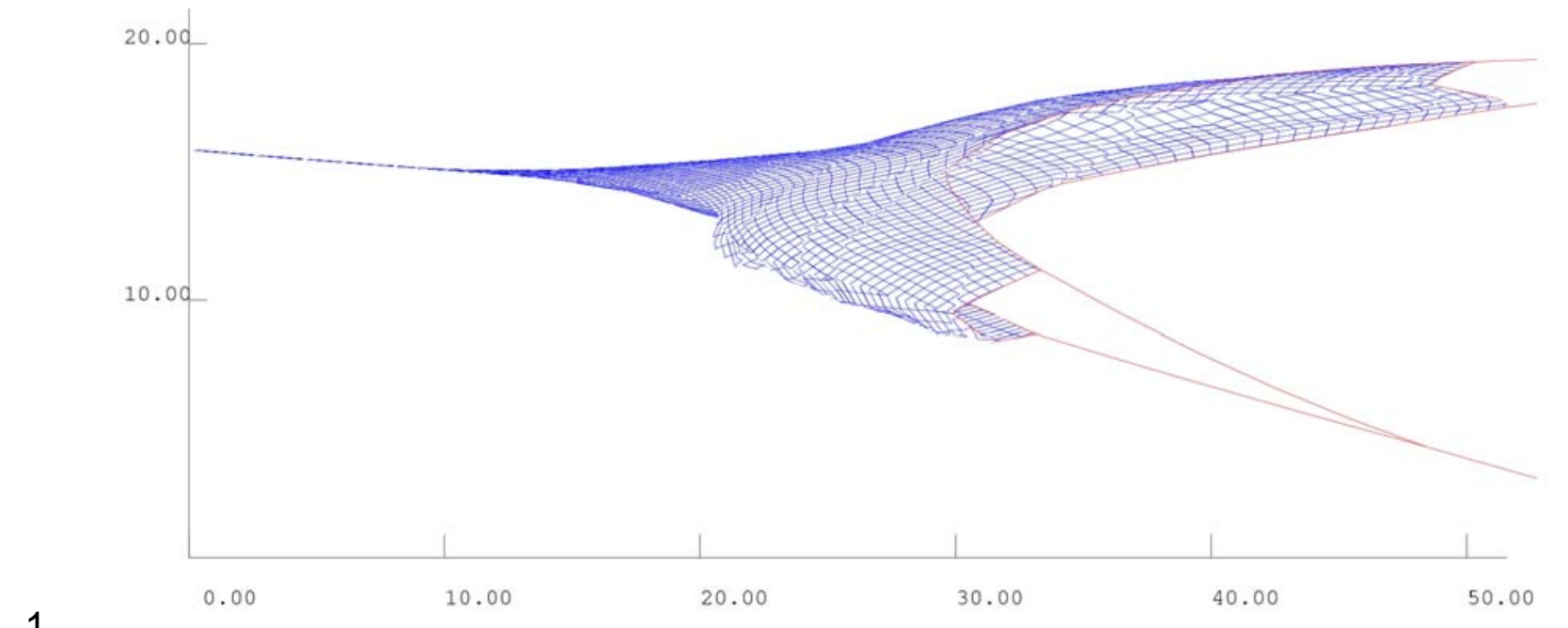

1

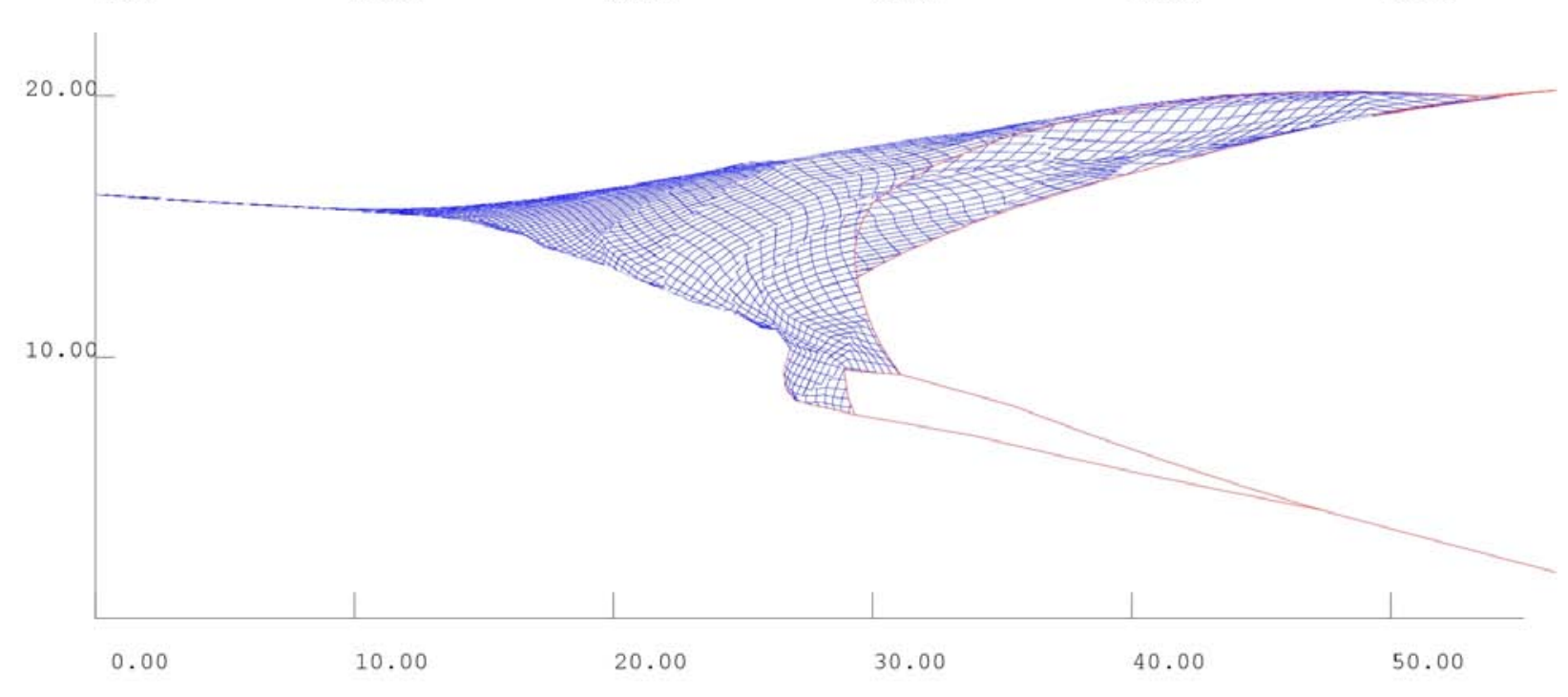

2

3 Figure 10: Shapes of the reference bottom trawl (top) and optimised one (bottom). Due to the

4 large number of twines only one twine out of ten is drawn. 
1 Table 1: Drag repartition between components for trawls: without (a) and with (b) catch on

2 Italian bottom trawl, without (c) and with (d) catch on a 57/52 pelagic trawl. These figures are 3 from the FEM model.

\begin{tabular}{|l|c|c|c|c|}
\hline & a & b & c & d \\
\hline Cables & $8 \%$ & $7 \%$ & $28 \%$ & $24 \%$ \\
Otter boards & $21 \%$ & $19 \%$ & $17 \%$ & $15 \%$ \\
Netting & $66 \%$ & $60 \%$ & $55 \%$ & $44 \%$ \\
Catch & $0 \%$ & $10 \%$ & $0 \%$ & $17 \%$ \\
Ground rope & $5 \%$ & $4 \%$ & - & - \\
\hline Total & $100 \%$ & $100 \%$ & $100 \%$ & $100 \%$ \\
\hline
\end{tabular}

4 
1 Table 2: Few results of calculations of drag and swept area for a modification of 5\% on the

2 pelagic trawl for the first step of optimisation.

\begin{tabular}{|c|c|c|c|c|c|}
\hline Panel & Node & Modification & Drag (N) & Swept area $\left(\mathrm{m}^{2}\right)$ & Drag/swept area $\left(\mathrm{N} / \mathrm{m}^{2}\right)$ \\
\hline \multicolumn{3}{|c|}{ Reference } & 67226 & 199 & 337.8 \\
\hline \multirow[t]{4}{*}{1} & 1 & $\mathrm{~N}$ & 67192 & 224 & 299.7 \\
\hline & 1 & S & 67238 & 200 & 337.0 \\
\hline & 1 & $\mathrm{~W}$ & 67220 & 199 & 338.0 \\
\hline & 1 & $\mathrm{E}$ & 67230 & 199 & 337.8 \\
\hline \multirow[t]{4}{*}{1} & 2 & $\mathrm{~N}$ & 67718 & 226 & 300.1 \\
\hline & 2 & S & 67686 & 217 & 311.9 \\
\hline & 2 & W & 67230 & 199 & 338.2 \\
\hline & 2 & $\mathrm{E}$ & 672187 & 199 & 337.3 \\
\hline 2 & 1 & $\mathrm{~N}$ & 68598 & 249 & 275.8 \\
\hline
\end{tabular}

3 
1 Table 3: Effect of the discretisation size on the drag and on the swept area. Values of the

2 reference trawl are noted.

\begin{tabular}{|l|rrrrrrr|}
\hline Discretisation size $(\mathrm{m})$ & Ref. & 0.8 & 1 & 2 & 3 & 4 & 5 \\
\hline Drag $(\mathrm{N})$ & 67226 & 77728 & 81278 & 84150 & 82732 & 83706 & 78458 \\
Swept surface $\left(\mathrm{m}^{2}\right)$ & 199.0 & 401.5 & 431.5 & 480.9 & 552.3 & 469.9 & 466.9 \\
Drag per swept surface $\left(\mathrm{N} / \mathrm{m}^{2}\right)$ & 337.8 & 193.6 & 188.4 & 175.0 & 149.8 & 178.2 & 171.1 \\
Reduction & 0 & 0.43 & 0.44 & 0.48 & 0.56 & 0.47 & 0.49 \\
\hline
\end{tabular}

3 
1 Table 4: Effect of the modification size on the drag per swept area of the optimised trawl.

2 Values of the reference trawl are noted.

\begin{tabular}{|l|rrrrr|}
\hline Modification & Reference & $1.00 \%$ & $2.00 \%$ & $4.00 \%$ & $8.00 \%$ \\
\hline Drag per swept surface $\left(\mathrm{N} / \mathrm{m}^{2}\right)$ & 337.8 & 170.6 & 183.1 & 149.8 & 153.1 \\
& 0 & 0.50 & 0.46 & 0.56 & 0.55 \\
\hline Reduction relatively the reference & 0 & & & & \\
\hline
\end{tabular}

3 
1 Table 5: Comparison of the reference pelagic trawl with the optimised one in term of time at

2 sea and fuel cost.

\begin{tabular}{|c|c|c|}
\hline & Reference trawl & Optimised trawl \\
\hline Trawl drag & 67226 & $77728 \mathrm{~N}$ \\
\hline Trawl swept area & 199 & $401 \mathrm{~m}^{2}$ \\
\hline Towing duration & 200 & 99days/y \\
\hline Towing distance & 14818 & $7346 \mathrm{Km} / \mathrm{y}$ \\
\hline Filtered volume & 2.95 & $2.95 \mathrm{Km}^{3} / \mathrm{y}$ \\
\hline Drag energy & 277 & 159Mwh/y \\
\hline Fuel volume & 259 & $148 \mathrm{~m}^{3} / \mathrm{y}$ \\
\hline Fuel cost & 181020 & $103758 € / y$ \\
\hline
\end{tabular}

3 
1 Table 6: Comparison of the reference bottom trawl with the optimised one in term of time at

2 sea and fuel cost.

\begin{tabular}{|l|r|r|}
\hline & Reference trawl & Optimised trawl \\
\hline Trawl drag & 64450 & $63910 \mathrm{~N}$ \\
Trawl swept width & 21.68 & $29.37 \mathrm{~m}$ \\
Towing duration & 200 & 148 days $/ \mathrm{y}$ \\
Towing distance & 12168 & 264 \\
Swept surface & 218 & $893 \mathrm{Km} / \mathrm{y}$ \\
Drag energy & 204 & $264 \mathrm{Km}^{2} / \mathrm{y}$ \\
Fuel volume & 142513 & $159 \mathrm{Mwh} / \mathrm{y}$ \\
Fuel cost & & $149 \mathrm{~m}^{3} / \mathrm{y}$ \\
\end{tabular}

3 